\title{
Coeliomesenteric trunk - a rare variation to be aware of
}

\author{
Joel Arudchelvam \\ Teaching hospital Anuradhapura
}

Key words: Coeliomesenteric trunk; coelio mesenteric trunk embryology; coeliac axis superior mesenteric artery variations; abdominal aorta branches; aorta branch variations

\section{Introduction}

The Coelic axis (CA) and the Superior Mesenteric Artery (SMA) are the anterior visceral arteries of the Abdominal Aorta. CA arises at the level of lower 12th thoracic vertebra while SMA arises at the first Lumbar vertebral level. Normally CA divides into Common Hepatic (CHA), Left Gastric (LG) and Splenic Arteries (SA). These branches supply liver, spleen stomach, upper duodenum and pancreas. The SMA supplies the small intestine. Rarely these two arteries have a common origin due to variations in the embryological development i.e. Coeliomesenteric Trunk (CMT) $[1,2]$. It is important to be aware and detect such variation to avoid complications during interventions.

\section{Case presentation}

A 71-year-old female underwent contrast-enhanced Computed Tomography (CT) for non-specific abdominal pain at the Teaching Hospital Anuradhapura, Sri Lanka. CT was done with Multidetector Toshiba Aquilion Prime CT machine with $60 \mathrm{ml}$ of Omnipaque 300 (iohexol) contrast agent and arterial images were obtained after a delay of about 25 seconds. Images were interpreted after 3D reconstruction in the console. There was an incidental finding of CMT arising at the first lumbar vertebral level. The CMT divided into CA and SMA. The CA divided further into CHA, LG and SA(figure 1,2). There were no other abnormalities detected.

\section{Discussion and conclusion}

The reported incidence of CMT is about $2.7 \%$ to $5.4 \%[2,3]$. CA and SMA develop by a series of ventral branches (Omphalo Mesenteric Arteries -OMA) form the dorsal aorta which appears during the embryological period (figure 3). A longitudinal vessel connects the OMA [1]. First OMA develops into CA while the fourth develops into SMA. CHA,

\footnotetext{
Correspondence: Joel Arudchelvam

E-mail: joelaru@yahoo.com

Received: 13-09-2019 Accepted: 12-10-2019

(i) http://orcid.org/0000-0002-4371-4527 DOI: http://doi.org/10.4038/sljs.v37i3.8621
}
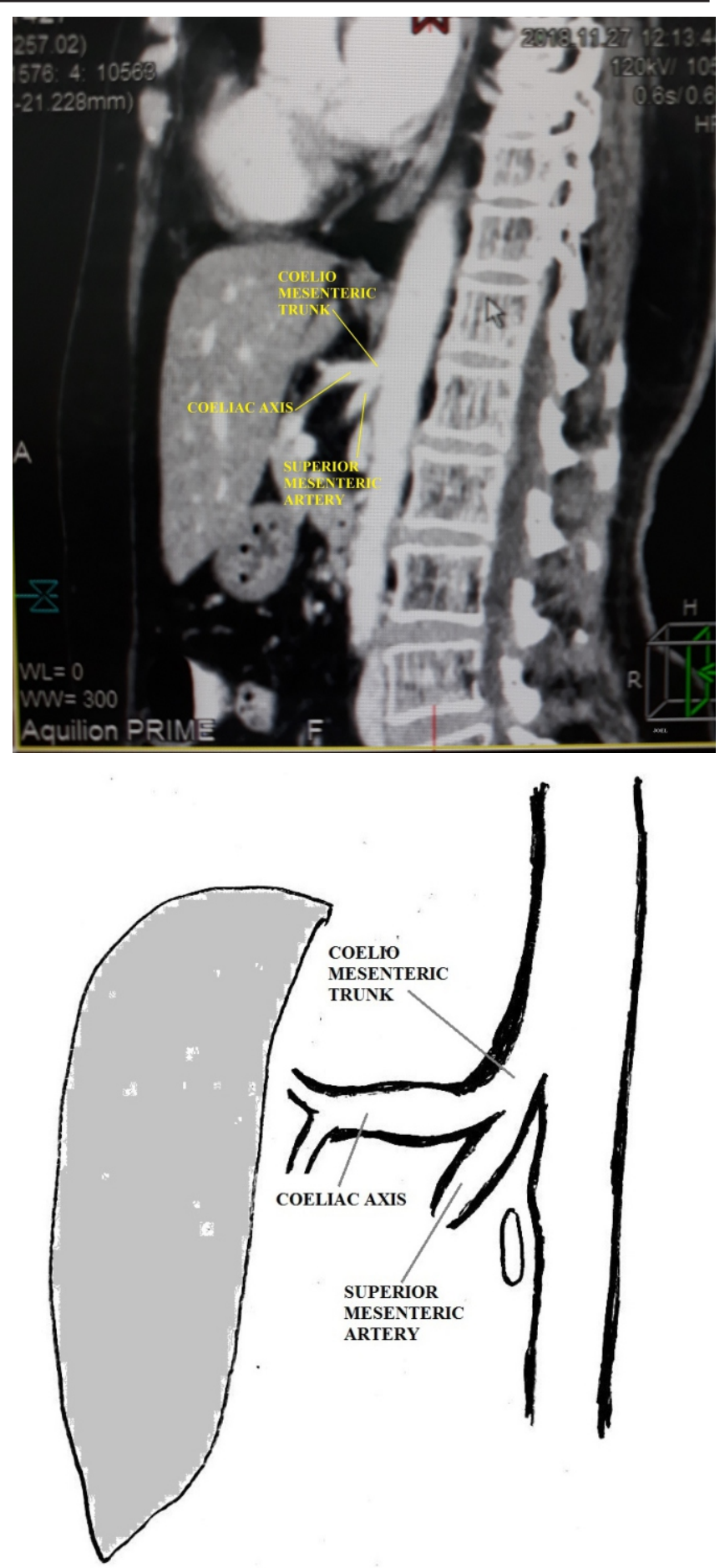

Figure $1 \& 2$. Coelio mesenteric trunk 

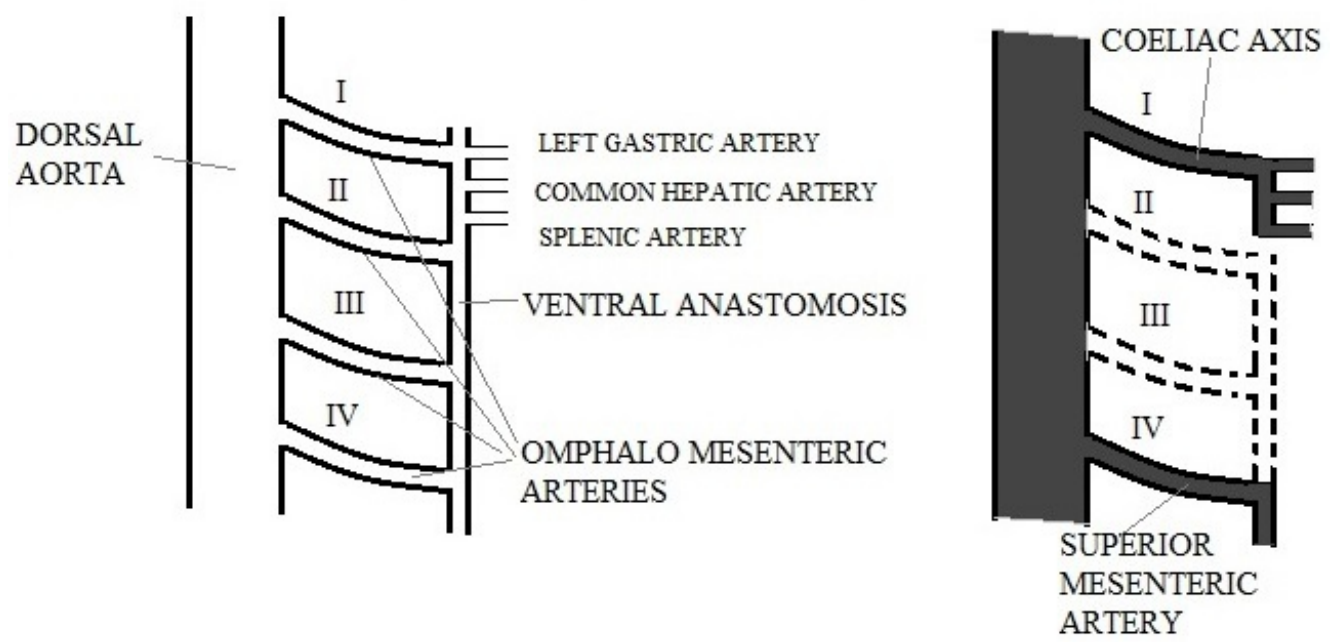

Figure 3. Coelio mesenteric trunk development

LG and SA develop from this longitudinal anastomosis. The part of the longitudinal anastomosis distal to these branches and the second, third OMA disappear thus separating CA and SMA. If the First or the fourth OMA disappear CMT develops [1]. Awareness of this variation is important to plan surgeries, interventional procedures and to avoid complications.

All authors disclose no conflict of interest. The study was conducted in accordance with the ethical standards of the relevant institutional or national ethics committee and the Helsinki Declaration of 1975, as revised in 2000

\section{References}

1. Celiacomesenteric trunk . Çavdar, S., Şehirli, Ü., \& Pekin, B. 4, 1997, Clinical Anatomy:The Official Journal of the American Association of Clinical Anatomists and the British Association of Clinical Anatomists, Vol. 10, pp. 231-234.

https://doi.org/10.1002/(SICI)1098-2353(1997)10:4<231::AIDCA2 $>3.0 . \mathrm{CO} ; 2-\mathrm{V}$

2. A Study Of Common Coelio-Mesenteric Trunk with Variations in The Extra Hepatic Arterial System and Its Clinical Significance. P.S.Chitra, S.Kalaiyarasi. 3, 2016, International Journal of Anatomy and Research, Vol. 4, pp. 2701 - 2705. https://doi.org/10.16965/ijar.2016.311

3. Coeliomesenteric trunk stenosis-a rare variation causing mesenteric ischaemia. Agarwal, A. K., Youssef, M. K. I., Doyle, G. J., \& Wood, C. P. L. 4, 2000, European Journal of Vascular and Endovascular Surgery, Vol. 20, pp. 405-406.

https://doi.org/10.1053/ejvs.2000.1202

\section{Learning Points:}

- Coeliomesenteric trunk is a rare variation.

- Awareness of this will prevent potential disasters. 